\title{
A avaliação na escola: um histórico de exclusão social-escolar ou uma proposta sociocultural para a inclusão?
}

Sueli Salles Fidalgo

PUC-SP - Faculdade Casper Líbero

\begin{abstract}
Based on discussions about the different kinds of assessment used in education (BACHMAN, 1990; ALVAREZ-MÉNDEZ, 2002), this paper firstly examines the theoretical backgrounds that have traditionally supported actions taken within the school environment. Then, more inclusive forms of assessment are discussed, maintained by the view that language is the key instrument to either exclude participants from the learning-assessing-teaching procedure or to otherwise include them. Thus, this paper aims at showing that assessing students would be more inclusive if three main concepts were taken into account, i.e.: (1) that assessing is part and parcel of teaching-learning, (2) that negotiation is a key element to organize the higher mental functions (VYGOTSKY, 1934), (3) that language is a zone of conflict in which ideology is challenged and knowledge, reconstructed (SCHNEUWLY, 1992).
\end{abstract}

Considerando as diferentes formas de avaliar usadas na educação (BACHMAN, 1990, ALVAREZ-MÉNDEZ, 2002), este artigo examina, primeiramente, o arcabouço teórico que tradicionalmente tem servido de apoio para a avaliação nas escolas. Em seguida, outras formas mais inclusivas de avaliar são discutidas, com base no conceito de que a linguagem é a ferramenta para manter ou transformar o status quo. Dessa forma, este artigo busca demonstrar que a avaliação de aprendizagem pode ser mais inclusiva se três conceitos essenciais forem levados em conta: (1) que a avaliação é indissociável do processo de ensino/aprendizagem, (2) que a negociação é elemento chave para a organização das funções psicológicas superiores (VYGOTSKY, 1934); (3) que a linguagem é zona de conflito para o questionamento da ideologia e a reconstrução do conhecimento (SCHNEUWLY, 1992).

\section{Introdução}

A julgar pelo crescente número de material publicado acerca de avaliação de aprendizagem, talvez possamos afirmar que a preocupação com as formas de avaliar está cada vez mais em evidência, tanto nas 
escolas quanto em pesquisas - um reflexo da preocupação escolar. Com efeito, só no Brasil, nos últimos dez anos, é possível destacar trabalhos como os de Afonso (2000), Almeida (2001), Fidalgo (2001), Hoffman (1993), Luckesi (1992, 1994), Romão (1998) e Romero (2000), dentre outros. Em outros países, autores como Bailey (1998), Katz (2000), Perrenoud (1999), Bonniol e Vial (2001), Coll e Martín (1999), Figari (1996) e O'Malley e Valdez Pierce (1996) também têm se debruçado sobre essa questão. Motivados pela busca de uma avaliação mais justa, esses autores têm questionado a finalidade de tipos mais normativos de avaliações, salientando que sua função parece ser, muitas vezes, a de hierarquicamente incluir alguns alunos à medida que exclui outros - dividindo crianças por sua origem sociocultural.

São vários os modelos discutidos por esses e outros autores, variando desde (1) uma avaliação como sinônimo de exames, mais tradicional, com questões cujo conteúdo só indiretamente seria usado na vida real, mas cuja forma foge totalmente de um uso real da língua (i.e., questões que testam a língua e não o uso, como preenchimento de lacunas, por exemplo), até (2) instrumentos de auto-avaliação, que, muitas vezes, não são aceitos pelos pais ou alunos como evidência de aprendizagem.

São também vários os nomes com os quais a avaliação somativa/ formativa (PERRENOUD, 1999), ou quantitativa/qualitativa, ou bancária/ dialógica (ROMÃO, 1998), ou estática/dinâmica (LUNT, 1994) tem sido tratada.

Neste artigo, olho para três dos principais modelos de avaliação utilizados em nossas escolas, a saber: a avaliação bancária, a centrada no aluno e a mediad(or)a. Traçando paralelos com os momentos históricos nos quais esses modelos se situam, discuto as concepções de ensino/aprendizagem que os embasam e proponho uma rediscussão (ou mesmo uma redefinição) de alguns dos termos com os quais tratamos a avaliação (acima citados).

\section{A tradição de exames: um pouco da história}

Historicamente falando, a avaliação foi uma atividade, inicialmente, trazida para a educação por um desejo de controle pelo exame, que existe desde o século XVI (Cf. LUCKESI, 1994, p. 21-22). Era, naquele período, uma atividade com três funções diferentes, para três grupos 
também distintos, de destaque na sociedade: (1) os jesuítas, que devotavam atenção especial "ao ritual de exames e provas" com o intuito de orientar as práticas escolares para que práticas heréticas (principalmente em relação ao protestantismo) fossem combatidas; (2) Comênio (protestante), que, por outro lado, ressaltava a importância do medo como "excelente fator para manter a atenção dos alunos" e, assim, estimulava o uso de exames finais como estratégia de ensino, chamada por Luckesi (op.cit, p. 22) de pedagogia comeninana; (3) a sociedade burguesa, que usava os exames como forma de manter sua "seletividade escolar e seus processos de formação das personalidades dos educandos" ( ibid.) - logo, aprimorava o controle por meio de exames.

No entanto, como nos lembra Chardenet (2000, p. 47-48), nem sempre fora assim. Nas antigas Grécia e Roma, confiava-se plenamente na relação entre mestre e discípulo; na Idade Média, havia uma organização social em torno de profissões - que eram passadas de pais para filhos. Mais tarde, o procedimento de examinar foi trazido da China para a Europa por viajantes, mas foi só com a Revolução Industrial que os exames nacionais foram criados no ocidente, motivados, em primeiro lugar, pela necessidade de se encontrar mão-de-obra especializada (CHARDENET, 2000, p. 47). Mais tarde, a prática de exames foi aplicada nas escolas devido à crença de que princípios modernos de gerenciamento científico, utilizados para aumentar a produtividade, representariam também uma prática de sucesso em ambientes educacionais (Cf. SHEPARD, 2000, p. 4).

Ao ser trazida para a realidade escolar, a prática de exames mantinha suas características de disciplina psicométrica - similaridade com a área de pesquisa dita científica (ou positivista) que, segundo Stufflebeam (1969), se devia ao seu traço comum de tentar obter "conhecimento para a compreensão dos fenômenos educacionais e a solução de seus problemas".

A similaridade com a pesquisa não foi só essa. Norris (1993) acrescenta ao rol de semelhanças o fato de que tanto avaliadores quanto pesquisadores acabam modificando seu comportamento quanto ao planejamento e exercício de suas atividades em função da posição que adotam. É possível dizer que se modificam também em função dos resultados que os alunos obtêm nos exames. É o chamado efeito de refluxo - que será discutido mais adiante. Seja qual for o debate, o traço comum que parece ter ficado mais enraizado e que, ainda hoje, é visto 
como importante para a grande maioria de professores, é a questão da objetividade - o que veio a gerar também uma necessidade de quantificação dos resultados da avaliação (quantitativa ou somativa). No entanto, vários pesquisadores têm sustentado que essa é uma questão estéril, já que, estando sujeita à elaboração e correção por alguns sujeitos/agentes com poder e também com preferências, com humores, compreensões e atitudes diferentes em momentos diversos, toda avaliação seria, no fundo, subjetiva. Afinal, é elaborada e utilizada por seres humanos. Por esse motivo, Bonniol e Vial (2001, p. 55) referem-se a essa discussão como "a ilusão de objetividade" e, discutindo Cardinet (1986), completam:

a própria idéia de que, na realidade, existe um nível verdadeiro de conhecimento do aluno (...) é agora colocada em dúvida quando vemos que basta mudar a forma da interrogação para transformar o sucesso em fracasso ou a aceitação em rejeição.

No entanto, ainda hoje, há quem defenda os testes ditos objetivos, cuja proposição inicial remonta a Thorndike, que, segundo Shepard (2000, p. 5), foi, pelo menos nos Estados Unidos, o responsável pelo desenvolvimento e predomínio desse tipo de instrumento. Em pesquisa, ao buscar a origem de conceitos de objetividade, encontraremos, dentre outros, Popper (1975), para quem "as ciências (...) baseiam-se em construtos teóricos que necessitam ser testados em sua veracidade" para que possam compor um corpus científico.

Em avaliação de aprendizagem, o processo foi semelhante. A partir de meados do século XX, tendo começado a investir mais em educação (Cf. VIANNA, 1997, p. 27), alguns governos sentiam também a necessidade de medir a qualidade de ensino. Ao buscarem uma forma de mensurar tal qualidade, surgiam problemas quanto ao conhecimento de quem construía e/ou utilizava os instrumentos de avaliação (VIANNA, idem). É possível que tenha sido esse o motivo de termos trazido a discussão de objetividade para as provas, uma vez que professores, via de regra, mal preparados e mal remunerados (cf. ESTEVE, 1999), não eram vistos pelos investidores e demais "acionistas" da educação como capazes de manter a confiabilidade e validade das provas e dos seus resultados, de acordo com o que exigiam seus empregadores. Isso deu origem ao que Romão (1998) chama de avaliação bancária - tomando emprestado o termo de educação bancária de Freire (1970, p. 58), porque onde se fazem depósitos, também se fazem retiradas. 


\section{A relação entre depositante e depositário: a avaliação bancária}

A avaliação bancária consistiria na capacidade do aluno de buscar nos seus "arquivos mentais" os depósitos ali deixados, exatamente como foram feitos, sem interpretação, sem acréscimos, sem qualquer tipo de juros ou deduções, e devolvê-los ao depositante, mediante requisição: a prova, o teste, o exame final. Nesse sentido, avaliação e testagem passam a ser conceitos sinônimos, uma vez que, tendo como meta a devolução "objetiva" dos conhecimentos depositados, a prova seria o único instrumento utilizado para a ampla tarefa de avaliar. Aos depositantes cabia o direito de requisitar extratos com informações ad hoc acerca dos depósitos feitos. Nem o momento de requisição, nem sua forma ou o conteúdo requisitado precisavam ser previamente discutidos - ou sequer informados - aos depositários. A aceitação do aluno em um grupo social, sua promoção como depositário (para outras séries), sua inclusão em determinados cursos dependeriam de seu resultado em tais momentos de reprodução de conhecimento.

Acreditava-se que, se a prova conseguisse cobrar ipsis litteris o que o professor havia ensinado (ou o que deveria ter ensinado) e se o aluno conseguisse repeti-lo, a influência das idiossincrasias dos professores teria sido anulada ou, pelo menos, bastante diminuída. A preocupação central era a de se encontrarem leis que dessem conta dos problemas de "fidelidade" das notas. Preocupava o fato de professores e examinadores diferentes não concordarem com as notas finais de alunos e/ou o fato de notas serem dadas por comparações entre os alunos, o que poderia denotar falta de critérios previamente estabelecidos e, portanto, falta de objetividade (Cf. BONNIOL; VIAL, 2001, p. 58-59). Foi por volta de 1950, então, que, para garantir essa objetividade, autores como Thorndike e Stanley (Cf. BONNIOL; VIAL, idem) começaram a estudar a questão da confiabilidade em avaliação, para verificar o que fazia as notas de testes variar (Cf. BACHMAN, 1990, p. 163). Esse conceito - já existente na área de pesquisa - foi, posteriormente, alvo de diversas investigações para a elaboração de provas (BACHMAN, op. cit.; HUGHES, 1989; PORTER, mimeo; WEIR, 1993). Outros conceitos, que também receberam bastante atenção, foram os de validade $e$ praticabilidade. Juntos, os três termos são considerados, até hoje, qualidades primárias de testes e exames e serão definidos a seguir. 
De um modo geral, a validade trata do "grau pelo qual as notas de um teste permitem tirar conclusões adequadas, significativas e úteis" em relação ao(s) objetivo(s) do teste (Cf. MILANOVIC, 1998, p. 394). Dentre os diversos conceitos de validade associados à avaliação, quatro serão definidos aqui por trazerem implicações para os outros tipos de avaliação definidos mais adiante. São eles: (1) a validade de conteúdo - ou o que se quer avaliar -; (2) a validade de construto - se a avaliação mede exatamente a habilidade que deve medir-; (3) a validade aparente, que verifica como as pessoas vêem a avaliação, se acreditam nos instrumentos e nos processos envolvidos; e (4) o efeito de refluxo, que se refere ao efeito que os resultados obtidos em provas e testes têm sobre o ensino, sobre a prática educativa (HUGHES, 1989; WEIR, 1993). Um dos efeitos da validade de refluxo no ensino é o que Luckesi (1994, p. 25) chama de pedagogia do exame, ou seja, a prática de pautar o currículo escolar nos exames que o aluno poderá vir a fazer um dia (como o vestibular, por exemplo). O exame e não o currículo ou o projeto político pedagógico torna-se, então, o texto prescritivo para o ensino (Cf. BONNIOL; VIAL, 2001, p. 58) - e mesmo para a elaboração dos documentos escolares supracitados.

Tão importante quanto a validade é o conceito de confiabilidade, definido como a consistência ou estabilidade das medidas de um teste, considerado confiável se seus resultados forem consistentes em diferentes situações de exame. É em função desse conceito que, muitas vezes, vemos em escolas novas pedagogias serem testadas com a utilização de grupos de controle e grupos experimentais, antes de se tomar uma decisão quanto à sua aplicação mais ampla.

O último termo, praticabilidade, diz respeito à criação e uso de um teste. Para Hughes (1989, p. 47), considerando-se todos os outros conceitos, é também importante que os testes sejam de elaboração, administração, correção e interpretação fácil e pouco dispendiosa.

Como ressaltado anteriormente, esse tipo de avaliação tem seu aporte educacional em uma concepção bancária de ensino. Em pesquisas acerca da aprendizagem e desenvolvimento humano, temos o trabalho de Skinner (dentre outros comportamentalistas), que julgava ser necessário "medir, comparar, testar, (...) prever e controlar eventos de modo a explicar o objeto de investigação" (Cf. DAVIS; OLIVEIRA, 1990, p. 31). Nas palavras de William e Burden (1997, p. 8), essa preocupação poderia ser definida como método experimental que compõe uma 
filosofia investigativa conhecida como 'positivismo lógico'. Muito comum na época skinneriana, essa filosofia partia da premissa de que o conhecimento e os fatos poderiam ser descobertos a partir de experimentos nos quais as condições deveriam ser cuidadosamente controladas e as hipóteses rigorosamente testadas.

Esse rigor com o controle de eventos foi provavelmente um dos fatores que fez com que os comportamentalistas rejeitassem o erro como parte do processo de aprendizagem, sendo essa rejeição essencial para inibir a formação de hábitos considerados impróprios. Hoje, essa filosofia educacional e avaliativa ainda existe no âmbito escolar. Não sem razão, Hoffman (2000, p. 11) alerta que o exame permanece "ainda, como um dos mais sérios intentos de (...) escolas, que negam a individualidade de cada educando em razão de parâmetros avaliativos perversos e excludentes." No entanto, essa pedagogia do exame já convive com as demais formas de avaliar que serão discutidas a seguir.

\section{Autonomia na avaliação: Centrar o processo no aluno?}

Em meados do século passado, paralelamente às conclusões de que pesquisas na área de humanas já não poderiam ser aceitas de maneira tão controlada ou psicométrica, também as formas de avaliar foram questionadas, uma vez que já se chegara à conclusão de que o ensino por repetição de estruturas não garantia conhecimento para a vida. Em suas tentativas de trazer o aluno (e não um conteúdo sem função) para o centro do processo de ensino/aprendizagem, diversos educadores propuseram formas de avaliar ditas mais democráticas.

A partir daí, outros termos surgiram para tratar de avaliação, tais como: (1) avaliação qualitativa, que segundo os Parâmetros Curriculares Nacionais (PCN, 1998, p. 81) é entendida "como um conjunto de atuações que têm a função de alimentar, sustentar e orientar a intervenção pedagógica" e não de julgar sucessos ou fracassos; (2) formativa, cujo objetivo é de regulação. Interessa-se pelos procedimentos que levam o aluno a aprender. Opõe-se, assim, à avaliação somativa, preocupada com o controle, com resultados e produtos adquiridos (Cf. BONNIOL, 1989). Também se opõe à avaliação normativa, comprometida com a hierarquização de alunos por seus resultados e muitas vezes por seu nível social. 
A primeira se assemelha bastante ao conceito de pesquisa qualitativa, já que não faz da nota final, da questão psicométrica, sua essência. Por outro lado, é ampla o bastante para permitir uma variedade de práticas, desde a simples observação e valorização até a utilização de diversas provas - embora estas últimas sejam momentos estáticos de avaliação (LUNT, 1994, p. 226) - ao longo de um curso de tempo, desde que dêem subsídios para a alimentação, sustentação e orientação de intervenções pedagógicas.

A abordagem formativa, por sua vez, traz outras implicações: em avaliação formativa, definida como aquela que está a serviço da regulação da aprendizagem (PERRENOUD, 1999; BONNIOL, 1989) e que está diretamente ligada à idéia de revisão, re-elaboração (SCRIVEN, 1967), não caberia uma concepção linear de aprendizagem, uma vez que os próprios conceitos de linearidade e de re-elaboração são contraditórios. No entanto, o termo permanece usado tanto por quem acredita em um desenvolvimento maturacional, que antecede a aprendizagem ou em uma construção mais individual de conhecimentos (ZABALA, 1996, p. 193), quanto por aqueles que defendem a aprendizagem como um processo de fora para dentro (SCRIVEN, 1967) e até por quem cultiva ideais socioculturais em educação (ROMERO, 2000). Um dos instrumentos mais utilizados, no início desse processo de quebra com a avaliação bancária, foi a auto-avaliação. No entanto, essa prática logo provou que pouca ou nenhuma autonomia era permitida, de fato, ao aluno. A auto-avaliação, como esclarece Rabelo (1998, p. 79), parecia demonstrar uma prática democrática "em nome do não controle, da não arbitrariedade, da não classificação", mas as pessoas não percebem que essa forma de avaliar não se encontra "nem transparente, nem legítima" para aqueles que a utilizam.

Como a maioria dos alunos não aprendeu a se auto-avaliar - uma vez que esses não são formados por princípios de auto-regulação, planejamento de sua própria aprendizagem, ou pelo que Vygotsky (1934) chamou de funções mentais superiores (processo metacognitivo) - a avaliação apreciativa ou interpretativa (ou centrada no aluno), na realidade, via de regra, camufla o caráter de controle por não permitir que o aluno atue a partir do que conhece. Em outras palavras, estando a educação ainda pautada por conteúdos, é no processo cognitivo de reconhecimento desses conteúdos que o aluno estaria apto a atuar. No 
entanto, o que se pede que ele faça, no momento da auto-avaliação, é que atue no processo metacognitivo, cuja linguagem, função e forma de atuação desconhece inteiramente. Ainda que possa negociar com o professor a respeito da nota com a qual se avaliou, desconhecendo a linguagem argumentativa que organiza a negociação - sustentada por exemplos e por explicações (LIBERALI, 2000), o aluno sairia, mesmo assim, perdedor dessa "queda de braços."

Sem dúvida, considerando-se que é o professor ou o coordenador quem escolhe conteúdos, atitudes e procedimentos que devem ser avaliados (de acordo com objetivos e projetos pedagógicos que também eles traçaram); considerando-se que eles estabelecem os critérios para apreciação; considerando-se ainda que eles também são os responsáveis pela elaboração dos instrumentos de avaliação que os alunos utilizam, além, é claro, de caber a eles a palavra final (na maioria das vezes sequer sem uma negociação com os alunos), é difícil visualizar, em tal procedimento, uma prática realmente democrática ou libertadora.

É também difícil que tal avaliação seja aceita pelos demais participantes da comunidade escolar, como pais e alunos, acostumada que está em ter seus conhecimentos (ou os de seus filhos) "medidos" pelo poder do professor (LUCKESI, 1994). Gera-se, assim, um problema de credibilidade - ou, para usar os termos da pesquisa psicométrica, gerase um problema de validade aparente.

Estes são talvez os maiores problemas que defensores da autoavaliação têm de enfrentar: Como torná-la aceita pela comunidade? Como ser de fato libertadora, ouvindo/respeitando a voz avaliativa do aluno? Como servir de evidência da aprendizagem? É com essas indagações que muitos educadores mergulham em pesquisas sobre outros modelos de avaliar, como definidos a seguir.

\section{A linguagem de uma avaliação mediada e mediadora}

A avaliação formativa, assim como a qualitativa, tem sido modificada pelas constantes buscas de educadores por instrumentos que, de fato, permitam uma avaliação que alimente tanto a prática do professor quanto a do aluno. Em outras palavras, busca-se uma avaliação que seja qualitativa-formativa, ou dialógica (ROMÃO, 1998), ou mediad(or)a (FIDALGO, 2002) - que difere da concepção de avaliação mediadora 
(utilizada por HOFFMAN, 1993) porque, no conceito mais recente, a avaliação é definida não como um instrumento que auxilia o processo de ensino/aprendizagem, mas que é indivisível deste.

Avaliar ocorreria, portanto, em um processo dialógico que alimentaria tanto a prática pedagógica (do professor) - seguindo a definição de avaliação qualitativa encontrada nos PCN (1998) - quanto a do aluno (auto-monitoramento, planejamento, etc.) - de acordo com a definição de avaliação formativa (PERRENOUD, 1999). Além disso, não ocorreria somente entre professor e aluno, mas entre todos os envolvidos no processo avaliativo. Idealmente, seriam utilizados instrumentos de auto-avaliação, avaliação de pares e avaliação pelo professor - o que caracterizaria uma triangulação avaliativa (Cf. ALVAREZMÉNDEZ, 2002) e, mais do que fortalecer as evidências apresentadas ao final do processo, tornaria o aluno mais autônomo quanto ao monitoramento de sua aprendizagem.

Trata-se de uma avaliação, portanto, que seria mediada pelo processo de ensino/aprendizagem e mediadora deste. Esse tipo de avaliação tem base nos estudos socioculturais, uma vez que o conceito de mediação é um dos pilares da concepção vygotskiana de desenvolvimento - talvez seja mesmo o seu conceito primordial (Cf. LANTOLF, 2000).

A linguagem - instrumento semiótico - é, para Vygotsky (1934), uma ferramenta simbólica utilizada por humanos para agir sobre suas relações consigo mesmos ou com outros de sua cultura (Cf. LANTOLF, 2000, p. 1-26). É o que permite ao ser humano desenvolver as funções psicológicas superiores: atenção voluntária, memória intencional, planejamento, auto-monitoramento, etc., que utiliza para mediar ou regular tais relações - inclusive as de avaliação de ensino/aprendizagem. Logo, é possível afirmar que, se os alunos devem ser conhecedores daquilo que conseguem fazer e planejadores de suas ações futuras para o seu próprio desenvolvimento, é pela linguagem que isso será possível. Deve haver um tipo de linguagem (ou de texto) que permita ao aluno ser regulador de sua aprendizagem.

Para Werstch (1991, p. 29), ao contrário de muitas análises contemporâneas sobre a linguagem, cujo enfoque estaria na estrutura dos sistemas de signos, independentemente de qualquer papel mediador que possam ter, Vygotsky trata a linguagem e outros sistemas de signos como parte das ações humanas que medeiam - daí o termo ação mediada. 
Sendo uma ferramenta utilizada pelo pensamento para solucionar problemas de qualquer natureza, a linguagem é um espaço de conflito (Schneuwly, 1992) no qual conceitos científicos (adquiridos na escola) e cotidianos (trazidos para a escola) se cruzam, gerando momentos polifônicos (BAKHTIN; VOLOCHINOV, 1929), propícios à argumentação, dos quais pode resultar a aprendizagem, propulsora de desenvolvimento.

A avaliação pode também atuar na criação desse espaço, no qual a mediação será essencial para resolver os conflitos surgidos, seja com a nota, seja com as representações acerca do que deveria ser internalizado pelo aluno ou mesmo com aquilo que de fato foi apropriado por ele. A esse respeito, diz Vygotsky (1934, p.118): “(..) aprendizado adequadamente organizado resulta em desenvolvimento mental e põe em movimento vários processos de desenvolvimento (...)," o que demonstra uma visão não teleológica da aprendizagem ou da avaliação. Não sendo um processo retilíneo, como queriam os defensores de outras teorias de desenvolvimento, a aprendizagem se sustenta justamente pela negociação dos conceitos trazidos para o espaço de construção do conhecimento.

Vale lembrar também que, ainda para Vygotsky, as funções psicológicas ocorrem em primeiro lugar em atividades coletivas, sociais - como funções interpsíquicas - e, posteriormente, em atividades individuais - funções intrapsíquicas. Trazendo esses princípios para o tema da avaliação, seria importante lembrar que também nessa área a aprendizagem se daria, em primeiro lugar, na alter-avaliação para, posteriormente, ser possível uma auto-avaliação, i.e.: lembrar da necessidade de se pensar em formas de (auto-)avaliação que sejam atividades sociais (como a avaliação de pares), uma vez que o indivíduo não adquire a capacidade de monitorar sua aprendizagem naturalmente, com a maturidade, mas se constitui na interação com seus pares e sua cultura. Na realidade, é em interações dialógicas com seu meio, seus pares, sua cultura que o ser humano se apropria de saberes e outras ferramentas historicamente construídas - sendo a avaliação mais uma delas.

Também a esse respeito, Van der Veer e Valsiner (1991, p. 210) discutem que:

(...) Vygotsky afirmava que em geral os sistemas de signos culturais são primeiramente dominados em um ato manifesto e só mais tarde podem começar a funcionar internamente, após um processo complexo de internalização. 
Parece-me, portanto, que também à avaliação caberia a função de mediar a ação humana de ensino/aprendizagem e ser por ela mediada, já que é parte desse sistema de instrumentos que compõem as funções psicológicas superiores.

Semelhantemente a Vygotsky, Bakhtin valoriza a característica sócio-histórica do desenvolvimento (Cf. HOLQUIST, 1990, p. 80) e, conseqüentemente, rejeita (1) a teoria que determina uma oposição mente-corpo (KRAMSCH, 2000, p. 139); (2) a existência de um fim teleológico e unitário (HOLQUIST, op. cit., p. 76). Além disso, ambos tratam a linguagem como ferramenta capaz de modificar indivíduos e sociedade (Cf. VYGOTSKY, 1934; BAKHTIN; VOLOCHINOV, 1929).

Sobre a função da linguagem, assim como para Vygotsky, Bakhtin; Volochinov (op. cit., p. 112) também concordam que "a expressão organiza a atividade mental", ao invés de ser por ela organizada.

Dessa forma, é possível concluir que, assim como a linguagem é ferramenta para modificar o mundo e ser por ele modificada, o ser humano é definido pela alteridade, pois "é impossível pensar no homem fora das relações que o ligam ao outro” (BARROS, 1997, p. 30).

É importante não perder de vista que haveria diferentes vozes e pontos de vista em cada interação e isso passaria duas perspectivas: a das vozes trazidas para a interação e a das interpretações e compreensões levadas ou feitas do(s) enunciado(s) que compõe(m) o diálogo que Bakhtin chama de ato de descodificação. A primeira perspectiva definese pelo conceito de polifonia; a segunda, pela posição ocupada pelos participantes do diálogo, ou, segundo Holquist (op. cit., p. 164), pela metáfora da visão que explica que o que vemos é determinado pela forma como vemos e a forma como vemos já foi determinada pela posição de onde vemos. Se essa discussão for pensada como base para a concepção de avaliação mediad(or)a ou mesmo dialógica (ROMÃO, 1998), será possível concluir, novamente, que é na interação e na negociação que o aluno aprenderá a avaliar a si e ao outro. É também nessa interação, bem organizada, que o professor poderá reconstruir suas concepções acerca de avaliação, redefinindo as posições ocupadas pelos participantes - incluindo-se como um participante, mas não necessariamente como aquele a quem caberia a palavra final.

A importância desse tipo de perspectiva para a avaliação de aprendizagem parece inquestionável. Poucos lingüistas e mesmo 
educadores negariam, hoje, que é possível dizer que o agente se apropria de palavras, anteriormente usadas por outros. Logo, necessita negociar seus significados com aqueles a quem essas palavras são dirigidas e cujas vozes são levadas em consideração no momento da enunciação. Dessa forma, em última análise, também é possível dizer que a auto-avaliação é uma apropriação da avaliação que o outro faz de nós. É possível concluir, portanto, que, assim como qualquer outro enunciado, a alter-avaliação deve ser negociada para que tenha significado co-construído e, por isso, verdadeiramente democrático.

Ao se levarem todas essas variáveis em consideração, percebe-se que as condições para que a (auto-) avaliação de aprendizagens aconteça não são dadas a priori, mas são construídas em um processo conflituoso de negociação, com a utilização de um instrumento (signo ou palavra-ação) que é também socialmente construído, é ferramenta que deve mediar a negociação e ser modificada por ela. Não havendo verdades universais, para Bakhtin (1986, apud THORNE, 2000, p. 238), a verdade, se puder ser alcançada, deverá se dar com uma pluralidade de esforços e será historicamente contextualizada. Logo, também em avaliação, é preciso que se conceda independência às diferentes vozes e que se negociem os significados dos valores, bem como o próprio uso da língua.

É necessário, então, que a avaliação seja também, de alguma forma, socialmente construída, se não em sua concepção (ideal), pelo menos em sua realização.

\section{Referências Bibliográficas}

AFONSO, A. J. Avaliação educacional: regulação e emancipação. São Paulo: Cortez, 2000. 151 p.

ALMEIDA, J. S. G. A avaliação da aprendizagem escolar e a função social da escola. 2001. 189f. Dissertação (Mestrado) - Programa de Pós-Graduação em História e Filosofia da Educação. Pontifícia Universidade Católica de São Paulo.

ALVAREZ-MÉNDEZ, J. M. Avaliar para conhecer, examinar para excluir. Porto Alegre: Artmed. 2002. 133 p. 
BACHMAN, L. F. Fundamental considerations in language testing. Oxford: Oxford University Press, 1990. 408 p.

BAILEY, K. M. Learning about language assessment. EUA: Newbury House, 1998. 258 p.

BAKHTIN, M.; VOLOCHÍNOV, V. N. Marxismo e filosofia da linguagem. Tradução do francês de Michel Lahud e Yara Frateschi Vieira. São Paulo: Hucitec, 1929/1999. 196 p.

BAKHTIN, M. Speech, genres and other late essays by Mikhail Bakhtin. Austin: University of Texas Press, 1986. apud THORNE, S. L. Second language acquisition theory and the truth(s) about relativity. In: LANTOLF, J. (Ed). Sociocultural theory and second language learning. Oxford: Oxford University Press, 2000. p. 219-244.

BARROS, D. L. P de. Contribuições de Bakhtin às teorias do discurso. In: BRAIT, B. (Org.). Bakhtin, dialogismo e construção do sentido. Campinas: Editora da Unicamp, 1997.

BONNIOL, J. J. Entre les deux logiques de l'évaluation en psychologie: approches théoriques et conditions méthodologiques. AECSE, n. 6, p.12-18, 1989.

BONNIOL, J. J.; VIAL, M. Modelos de avaliação: textos fundamentais. Tradução do francês de Cláudia Schilling. Porto Alegre: Artmed, 2001. 367p.

BRASIL. Secretaria de Ensino Fundamental. Parâmetros Curriculares Nacionais: terceiro e quarto ciclos do ensino fundamental, língua estrangeira, $1998.126 \mathrm{p}$.

CARDINET, J. Lápport de la théorie de la généralisabilité a l'évaluation sommative individualisée. Evaluation scolaire et mesure. Bruxelas: De Boeck, 1986.

CHARDENET, P. A Avaliação: Formação social, cognitiva e discursiva. Desafio para a educação. In: PAIVA, M. da G. G.; BRUGALLI, M. (Orgs.). Avaliação, novas tendências, novos paradigmas. Trad. Elsa Maria NitscheOrtiz. Porto Alegre: Mercado Aberto, 2000.

COLL, C.; MARTÍN, E. A avaliação da aprendizagem no currículo escolar: uma perspectiva construtivista. In: COLL, C et alii. O construtivismo na sala de aula. Tradução do espanhol de Cláudia Schilling. São Paulo: Ática, 1999.

DAVIS, C.; OlIVEIRA, Z. de. Psicologia na educação. São Paulo: Cortez. 1990. 125p. 
ESTEVE, J. M. O mal-estar docente: a sala de aula e a saúde dos professores. Bauru: Edusc, 1999.

FIDALGO, S. Aprendendo a ensinar(,) a avaliar. In: Intercâmbio. São Paulo: LAEL, v. XI, p. 117-124, 2001.

. (Auto-)Avaliação de Ensino-Aprendizagem: Ferramenta para formação de agentes críticos. 2002. 189f. Dissertação (Mestrado) - PUC, São Paulo.

FIGARI, G. Avaliar: que referencial? Porto: Porto Editora, 1996.

FREIRE, P. Pedagogia do oprimido. Rio de Janeiro: Paz e Terra, 1970.

HOFFMAN, J. Avaliação Mediadora: uma prática em construção da préescola à universidade. Porto Alegre: Mediação, 1993. 197 p.

. Pontos e contrapontos: do pensar ao agir em avaliação. Porto Alegre: Mediação, 2000. 140 p.

HOLQUIST, M. Dialogism: Bakhtin and his world. London: Routledge, 1990.

HUGHES, A. Testing for language teachers. Cambridge: Cambridge University Press, 1989.

KATZ, A. Changing paradigms for assessment. In: SNOW, M. A. (Ed.). Implementing the ESL standards for pre-K -12 students through teacher education. Virginia: TESOL, 2000. 278p.

KRAMSCH, C. Social discursive constructions of self in L2 learning. In: LANTOLF, J. (Org.). Sociocultural theory and second language learning. Oxford: Oxford University Press, 2000. p.133-154.

LANTOLF, J. Introducing sociocultural theory. In: LANTOLF, J. Sociocultural theory and second language learning. Oxford: Oxford University Press, 2000. p. 1-26.

LIBERALI, F.C. Argumentative Processes in Critical Reflection. The ESPecialist. São Paulo: EDUC, v. 21, n. 1, p. 69-86, 2000.

LUCKESI, C. C. Avaliação da aprendizagem escolar. sendas percorridas. 1992. 452f. Tese (Doutorado) - Programa de Pós-Graduação em Filosofia da Educação. Pontifícia Universidade Católica de São Paulo. V. I e II.

Avaliação da aprendizagem escolar. São Paulo: Cortez. 1994. 180 p.

LUNT, I. A prática da avaliação. In: DANIELS, H. (Org.). Vygostky em foco: pressupostos e desdobramentos. Tradução do inglês de Elisabeth J. Cestari e Mônica Saddy Martins. Campinas: Papirus. 1994. p. 219-254. 
MILANOVIC, M.. Studies in language testing 6: Multilingual glossary of language testing terms, prepared by ALTE members. Cambridge: Cambridge University Press, 1998. p.360-396.

NORRIS, N. Understanding educational evaluation. London: Kogan Page, 1993.

O'MALLEY, J. M.; VALDEZ PIERCE, L. Authentic assessment for English language learners: Practical approaches for teacher. New York: AddisonWesley, 1996. 268 p.

PERRENOUD, P. Avaliação: da excelência à regulação das aprendizagens. Entre duas lógicas. Tradução do francês de Patrícia Chittoni Ramos. Porto Alegre: Artmed, 1999. 181 p.

POPPER, K. R. A lógica da pesquisa científica. In: SCHLICK, Moritz; CARNAP, Rudolf; POPPER, Karl R. (Coletânea de textos). Ospensadores. Abril Cultural. E. Victor Civita: São Paulo, 1975.

PORTER, D. Spoken Language. Comunicação proferida no curso de verão de 1998. Reading: Centre for Applied Linguistics, University of Reading. 1998 (mimeo).

RABELO, E. H. Avaliação: novos tempos, novas práticas. Petrópolis: Vozes, 1998.

ROMÃO, J. E. Avaliação dialógica: desafios e perspectivas. São Paulo: Cortez \& Instituto Paulo Freire, 1998. 136 p.

ROMERO, T. Analisando um instrumento de avaliação. Revista Álvares Penteado, FECAP, v.2, n.5, dez. 2000.

SCHNEUWLY, B. Contradição e desenvolvimento: Vygostky e a pedologia. Comunicação para o workshop "Aprendizagem e desenvolvimento, zona de desenvolvimento", Universidade de Bordeaux II, Bordeaux, 1992

SCRIVEN, M. The methodology of Evaluation. Perspectives of Curriculum Evaluation. AERA. Monograph 1, Rand McNally and Co. Chicago, 1967.

SHEPARD, L. A. The role of assessment in a learning culture. Educational researcher, v. 29, n. 7, p. 4-14, Oct. 2000.

STUFFLEBEAM, D. L. Evaluation as enlightment for decision making. In: BEATTY, W. H. (Ed). Improving educational assessment and an inventory of measures of affective behavior. Washington, D.C.: NEA, 1969. 
THORNE, S. L. Second language acquisition theory and the truth(s) about relativity. In: LANTOLF, J. (Ed). Sociocultural theory and second language learning. Oxford: Oxford University Press, 2000. p. 219-244.

VAN DER VEER, R.; VALSINER; J. Vygotsky, uma sintese. São Paulo: Loyola, 1991/1996.

VIANNA, H. M. Avaliação educacional e o avaliador. 1997. Tese (Doutorado) - Programa de Pós-Graduação em Psicologia da Educação, Pontifícia Universidade Católica de São Paulo, São Paulo.

VYGOTSKY, L. S. A formação social da mente. Tradução do inglês por José Cipolla Neto, Luís Silveira Menna Barreto e Solange Castro Afeche. São Paulo: Livraria Martins Fontes, 1934/1984.

WEIR, C. Understanding \& developing language tests. Londres: Prentice Hall International, 1993.

WERSTCH, J. A necessidade da ação na pesquisa sociocultural. In: WERSTCH, J.; del RÍO, P.; ALVAREZ, A. Estudos socioculturais da mente. Tradução do inglês de Maria da Graça Gomes Paiva e André Rossano Teixeira Camargo. Porto Alegre: Artmed, 1991/1998.

WILLIAM, M.; BURDEN, R. Psychology for language teachers. Cambridge: Cambridge University Press, 1997.

ZABALA, A. Como trabalhar os conteúdos procedimentais em aula. Porto Alegre: Artmed, 1996/1999. 
$+1$ 